\title{
Implementasi Stepper 28BYJ-48 dan Servo MG996R sebagai Robot Lengan Pemanggang pada Alat Pemanggang Sate Otomatis Berbasis Arduino UNO
}

\author{
Angga Muhammad Satria Nugroho ${ }^{1}$, Rahmat Hidayat ${ }^{2}$, Arnisa Stefanie $^{3}$ \\ Jurusan Teknik Elektro Universitas Singaperbangsa, Karawang \\ JL. HS.Ronggo Waluyo, Puseurjaya, Kec. Telukjambe Tim., Kabupaten Karawang, Jawa Barat 41361 \\ ${ }^{1}$ angga.muhamadsn160250.student.unsika.ac.id \\ ${ }^{2}$ rahmat.hidayatestaff.unsika.ac.id \\ 3arnisa.stefaniedstaff.unsika.ac.id
}

Intisari - Di industri hampir semua pabrik-pabrik memanfaatkan sistem otomasi, dikarenakan hasil lebih cepat serta kualitas yang dihasilkan lebih baik tentunya menjadi faktor utama pemanfaatan sistem otomasi ini. Namun di industri rumahan seperti warung sate jarang sekai ditemukan pemanfaatan teknologi otomasi ini. Maka dibutuhkan alat yang mampu melakukan proses memanggsang sate secara otomatis. Didapatkan solusi dengan menciptakan robot lengan pemanggang yang mampu merekayasa proses pemanggangan sate berdasarkan mekanisme motor stepper 28BYJ-48 serta motor servo MG996R dengan kendali berbasis Arduino uno. Penelitian ini merupakan penelitian kualitatif, kuantitatif fan penelitian eksperimen. Pengambilan data dilakukan secara observasi langsung terhdap alat serta wawancara kepada pedagang sate. Hasil yang didapatkan bahwa robot lengan pemanggang mampu menjalankan tugasnya dengan optimal.

Kata kunci - Otomasi, sate, robot lengan.

Abstract - In industry, almost all factories use an automation system, because the results are faster and the quality is better, of course, are the main factors in the utilization of this automation system. However, in home industries such as satay stalls, it is rare to find the use of this automation technology. So we need a tool that is capable of baking the satay automatically. The solution was obtained by creating a roasting arm robot capable of engineering the satay roasting process based on the $28 \mathrm{BYJ}-48$ stepper motor mechanism and the MG996R servo motor with Arduino uno based control. This research is a qualitative research, quantitative experimental research fan. Data were collected by direct observation of the tools and interviews with satay traders. The results show that the roasting arm robot is able to carry out its duties optimally.

Keywords - Automation, satay, robotic arm.

\section{PENDAHULUAN}

Perkembangan teknologi telah
kehipuan
Pengaruhnya adalah hampir semua kalangan tak luput terhadap penggunaan teknologi, dikarenakan teknologi memiliki kemampuan untuk meringankan pekerjaan si pengguna, baik dari segi efisiensi waktu maupun tenaga. Teknologi saat ini tak lepas dari sebuah sistem kontrol untuk mengendalikan suatu proses agar mendapatkan hasil optimal, atau bisa kita sebut juga sebagai sistem otomasi.

Di dunia industri hampir semua pabrikpabrik memanfaatkan sistem otomasi, dikarenakan hasil lebih cepat serta kualitas yang dihasilkan lebih baik tentunya menjadi faktor utama pemanfaatan sistem otomasi ini. Namun di industri rumahan seperti warung sate jarang sekai ditemukan pemanfaatan teknologi otomasi ini. Warung sate pada umumnya masih menggunakan cara tradisional (manual) saat memanggang sate, yang tentunya sangat menyita waktu dan tenaga serorang pemanggang sate.

Penelitian kali ini bertujuan untuk mengatasi masalah, yaitu masih banyaknya warung-warung sate yang masih menggunakan konsep tradisional dalam proses memanggang. Masalah yang dihadapi adalah pemanggang harus membolak-balikan sate kemudian mengangkat nya setelah matang secara manual sehingga memakan waktu serta tenaga lebih bagi pemanggang. Maka dari itu dibuat perancangan sistem otomasi untuk proses pemanggangan sate secara otomatis.

Sistem otomasi ini dibuat dengan sistem yang diracang khusus untuk pengendalian robot lengan pemanggang. Berbeda dari penelitian sebelumnya yang mana mekanisme penggerak hanya dapat memutar sate $360^{\circ}$ saja. penelitian ini memiliki keunggulan, yakni mekanisme pada penelitian kali ini yaitu setiap kali sate matang maka secara otomatis mekanisme penggerak akan mengangkat sate tersebut, 
dan juga gerakan membolak-balikan sate akan terjadi sebanyak $180^{\circ}$ selama waktu tertentu, sehingga proses pemanggangan secara otomatis akan sesuai dengan pemanggangan sate secrara tradisional.

\section{TINJAUAN PUSTAKA}

\section{A. Arduino Uno}

Arduino Uno adalah sebuah kit elektronik atau bisa disebut papan rangkaian elektronik open source didalamnya terdapat komponen utama berupa chip mikrokontroler jenis Advanced Versatile RISC (AVR) berasal dari perusahaan Atmel, mikrokontroler adalah chip atau IC Integrated Circuit (IC) yang dapat diprogram dengan komputer. Tujuan menginput program pada komputer supaya input dapat dibaca oleh rangkiaan elektronik dan memproses input sehingga menghasilkan keluaran sesuai perintah program.[1]

\section{B. Motor Stepper 28BYJ-48}

Motor stepper adalah motor listrik DC brushless yang membagi rotasi secara penuh ke dalam sejumlah langkah yang sama. Prinsip kerjanya sama seperti motor DC, yaitu dengan cara pembangkitan medan magnet untuk memperoleh gaya tarik ataupun gaya lawan dengan menggunakan catu tegangan DC pada lilitan atau kumparannya.

Posisi motor stepper dapat diperintahkan bergerak atau menahan salah satu langkah tanpa sensor posisi untuk umpan balik, selama motor secara hati-hati diukur pada aplikasi sehubungan dengan torsi dan kecepatan. [5]

\section{C. $U L N-2003$}

ULN-2003 adalah sebuah integrated circuit (IC) dengan ciri memiliki 7 bit input, tegangan maksimal 50 Volt dan arus $500 \mathrm{~mA}$. IC ini termasuk jenis Transistor-Transistor Logic (TTL). Di dalam IC terdapat transistor darlington. transistor darlington merupakan dua buah transistor yang dirangkai dengan konfigurasi khusus untuk mendapatkan penguatan ganda sehingga dapat menghasilkan penguatan arus yang besar.[7]

\section{Motor Servo MG996R}

Motor servo adalah sebuah motor dengan sistem umpan balik di mana posisi dari motor akan diinformasikan kembali ke rangkaian kontrol yang ada dalam motor servo. Motor ini terdiri dari sebuah motor, serangkaian gear, potensiometer dan rangkian kontrol. Potensiometer berfungsi untuk menentukan batas sudut dari putaran servo. Sedangkan sudut dari sumbu motor servo diatur berdasarkan lebar pulsa yang dikirim melalui kaki sinyal dari motor [6].

\section{METODE PENELITIAN}

\section{A. Alur penelitian}

Penelitian ini dilakukan berdasarkan 5 tahapan, pertama melakukan studi kasus yaitu dengan membaca penelitian terdahulu maupun wawancara terhadap narasumber. Kedua melakukan perancangan mekanisme robot lengan pemanggang. Kemudian pada tahap ketiga mengimplementasikan rancangan yang telah dibuat. Setelah implementasi perancangan sesuai dengan yang diharapkan maka langkah selanjutnya melakukan pengujian terhadap robot lengan pemanggang. Lalu pada tahap kelima melakukan pengambilan data serta pembahasan hasil rancangan.

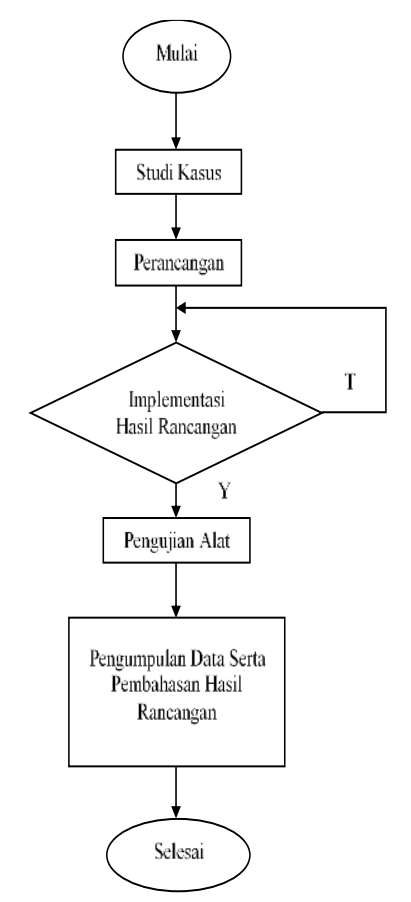

Gbr. 1 Flowchart Metodologi Penelitian 
B. Perancangan

1) Diagram model robot lengan pemanggang

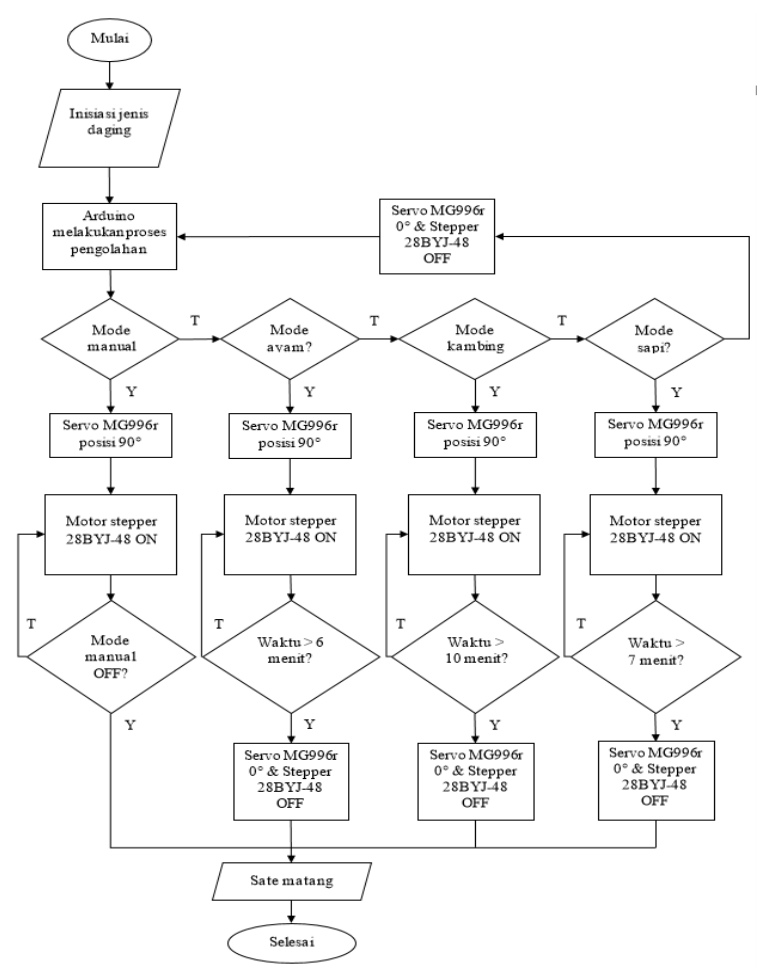

Gbr. 2 Flowchart Sistem Rancangan

2) Desain rancangan

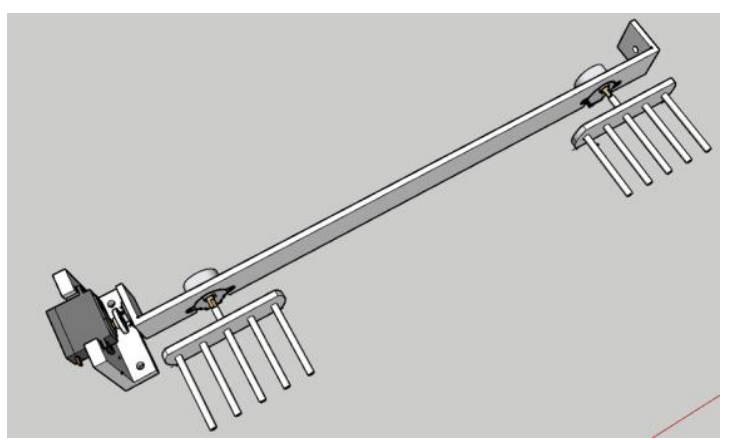

Gbr. 3 desain Robot Lengan Pemanggang

Gambar diatas menunjukan desain sistem lengan pemanggang. Desain dudukan untuk motor stepper 28BYJ-48 dibuat memanjang secara horizontal agar dapat diaplikasikan untuk memutar dua motor stepper, yang mana kedua motor stepper tersebut bertugas untuk membolak-balikan sate yang dipanggang. Pada ujung masing-masing motor stepper dihubungkan dengan alumunium untuk pegangan sate, masingmasing motor stepper dapat membolakbalikan lima tusuk sate. Posisi motor servo MG996r dibuat menyangga dudukan motor stepper, hal ini dimaksudkan agar motor servo mampu mengangkat dan menurunkan sate sesuai prinsip kerja sistem lengan pemanggang yang sudah dijelaskan sebelumnya.

\section{HASIL DAN PEMBAHASAN}

\section{A. Skema rangkaian robot lengan} pemanggang

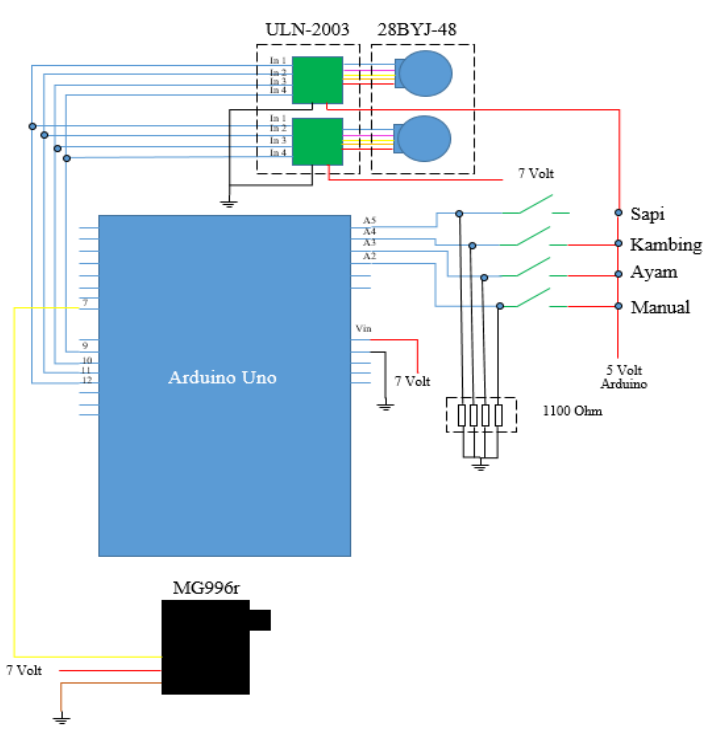

Gbr. 4 Rangkaian Robot Lengan Pemanggang

\section{B. Implementasi robot lengan pemanggang}

1) Implementasi perangkat keras

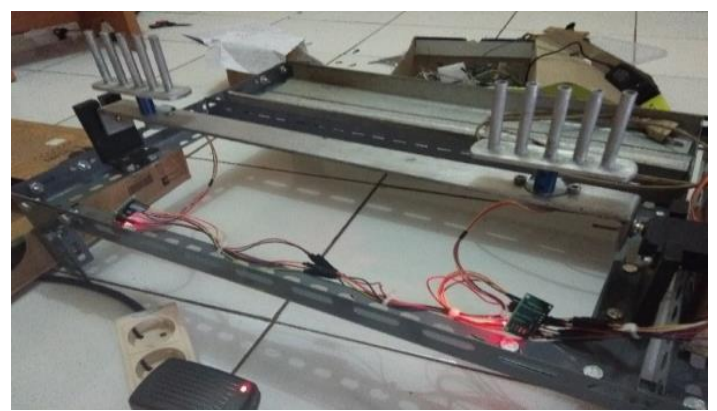

Gbr. 5 Bentuk Fisik Robot Lengan Pemanggang

\section{Tahap pengujian}

1) Pengujian motor servo MG996R

Pengujian pada motor servo MG996r dilakukan untuk mengetahui sudut putaran pada motor servo. Pengujian dilakukan dengan metode pengamatan. Pengamatan dilakukan dalam tiga kondisi. Kondisi yang diamati diantaranya, sebelum alat melakukan proses pemanggang, ketika alat sedang memanggang, serta ketika alat selesai 
memanggang. Dari pengamatan didapatkan hasil sebagai berikut:

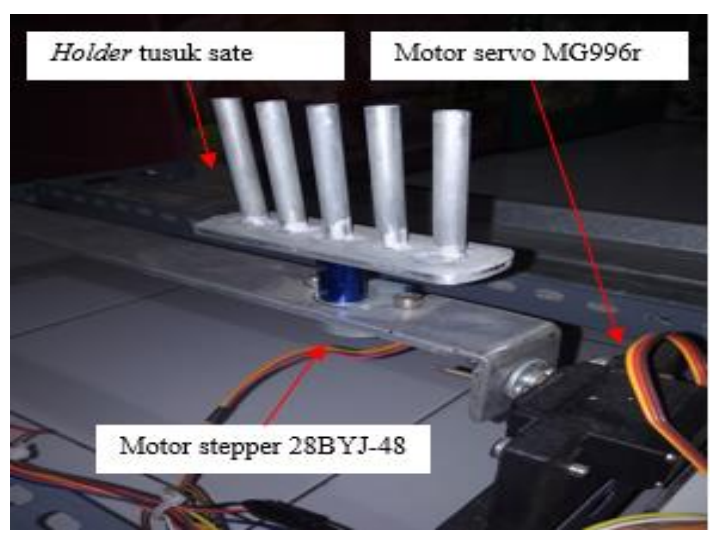

Gbr. 6 Tata Letak Komponen Robot Lengan Pemanggang

Tabel 1. Sudut Putaran Servo MG996R

\begin{tabular}{|l|c|c|}
\hline Kondisi alat & $\begin{array}{c}\text { Servo } \\
\left(\mathbf{0}^{\circ} \mathbf{- 9 0}\right.\end{array}$ & $\begin{array}{c}\text { Holder } \\
\text { tusuk sate } \\
\left(\mathbf{0}^{\circ} \mathbf{- 9 0}\right)\end{array}$ \\
\hline $\begin{array}{l}\text { Sebelum } \\
\text { memanggang }\end{array}$ & 0 & 90 \\
\hline $\begin{array}{l}\text { Sedang } \\
\text { memanggang }\end{array}$ & 90 & 0 \\
\hline $\begin{array}{l}\text { Selesai } \\
\text { memanggang }\end{array}$ & 0 & 90 \\
\hline
\end{tabular}

2) Pengujian motor stepper 28BYJ-48 Pengujian pada motor stepper 28BYJ48 dilakukan untuk mengetahui kinerja pada motor stepper, apakah sudah sesuai dengan yang diinginkan atau tidak. Pengujian dilakukan dengan metode pengamatan. Parameter yang diamati pada pengujian motor stepper diantaranya, sudut putaran, serta durasi jeda setelah motor stepper berputar $180^{\circ}$. Dari hasil pengamatan ini didapatkan hasil sebagai berikut:

Tabel 2. Hasil Pengujian Motor Stepper

\begin{tabular}{|l|c|c|}
\hline $\begin{array}{c}\text { Motor } \\
\text { Stepper } \\
\text { 28BYJ-48 }\end{array}$ & $\begin{array}{c}\text { Sudut } \\
\text { Putaran }\end{array}$ & $\begin{array}{c}\text { Durasi } \\
\text { Jeda } \\
\text { (Menit) }\end{array}$ \\
\hline $\begin{array}{l}\text { Motor } \\
\text { stepper 1 }\end{array}$ & $180^{\circ}$ & 1 \\
\hline $\begin{array}{l}\text { Motor } \\
\text { stepper 2 }\end{array}$ & $180^{\circ}$ & 1 \\
\hline
\end{tabular}

\section{PENUTUP}

Berdasarkan penelitian yang telah dilakukan didapati kesimpulan bahwa:

1. Motor setepper dan motor servo mampu bekerja sama dengan baik sehingga menciptakan mekanisme berupa gerakan lengan memanggang sate

2. Sudut putaran motor servo dan holder tusuk sate saling berbanding terbalik

3. Kedua motor stepper berputar dengan durasi jeda yang sama

\section{REFERENSI}

[1] Syahwil, Muhammad.2013. "Panduan Mudah Simulasi \& Praktek Mikrokontroler"

[2] Kadir, A.2017. "Pemrograman Arduino Menggunakan Ardublock". Yogyakarta Penerbit Andi

[3] Marselinus M.2016. "Sistem Alarm Kebakaran Menggunakan Sensor Infra red dan Sensor Suhu Berbasis Arduino Uno". Tugas Akhir. Jurusan Fisika, Fakultas Sains Dan Teknik, Universitas Nusa Cendana

[4] Saleh, Muhammad.2017. "Rancang Bangun Sistem Keamanan Rumah Menggunakan Relay”. Tugas Akhir. Program Studi Teknik Elektro, Universitas Suryadarma, Jakarta

[5] Nababan, R.Y.2020. "Rancang Bangun Alat Pemanggang Sate Otomatis Dengan Merode PWM Berbasis Mikrokontroler". Jurnal. Program Studi Teknik Informatika, STMIK Pelita Nusantara, Medan

[6] Hilal, Ahmad.2013. "Pemanfaatan Motor Servo Sebagai Penggerak CCTV Untuk Melihat Alat-Alat Monitor Dan Kondisi Pasien Di Ruang ICU”. Jurnal. Program Studi Diploma 3 Teknik Elektro, Fakultas Teknik, Universitas Diponegoro

[7] Ramdhani, Irwan.2012. "Aplikasi Driver Relay ULN-2003 Sebagai Penggerak Konveyor Otomatis Pengelompokan Buku Menggunakan Inisialisasi Barcode"

[8] Alassar, A. Z.2010. "modeling and control of 5DOF Robot Arm Using Supervisory Control. The Islamic University of Gaza". Electrical Engineering. Library IU Gaza.

[9] Hartopo, 1.2018. "Pengembangan Media Pembelajaran Lengan Robot 3 DOF pada Mata Pelajaran Perekayasaan Sistem Kontrol". Program Keahlian Teknik Elektronika Industri di SMK Negeri 2 Wonosari. Universitas Negeri Yogyakarta 